\title{
"The long-term relationship between enterprise risk management and bank performance: the missing link in Nigeria"
}

\begin{tabular}{|c|c|}
\hline AUTHORS & $\begin{array}{l}\text { Alaa M. Soliman } \\
\text { Adam Mukhtar } \\
\text { Moade F. Shubita id https://orcid.org/0000-0002-1465-9047 }\end{array}$ \\
\hline ARTICLE INFO & $\begin{array}{l}\text { Alaa M. Soliman, Adam Mukhtar and Moade F. Shubita (2018). The long-term } \\
\text { relationship between enterprise risk management and bank performance: the } \\
\text { missing link in Nigeria. Banks and Bank Systems, 13(1), 128-138. } \\
\text { doi:10.21511/bbs.13(1).2018.12 }\end{array}$ \\
\hline DOI & http://dx.doi.org/10.21511/bbs.13(1).2018.12 \\
\hline RELEASED ON & Thursday, 05 April 2018 \\
\hline RECEIVED ON & Saturday, 04 November 2017 \\
\hline \multirow[t]{2}{*}{ ACCEPTED ON } & Monday, 19 February 2018 \\
\hline & $((c))$ EY-No \\
\hline LICENSE & $\begin{array}{l}\text { This work is licensed under a Creative Commons Attribution-NonCommercial } 4.0 \\
\text { International License }\end{array}$ \\
\hline JOURNAL & "Banks and Bank Systems" \\
\hline ISSN PRINT & $1816-7403$ \\
\hline ISSN ONLINE & $1991-7074$ \\
\hline PUBLISHER & LLC “Consulting Publishing Company "Business Perspectives" \\
\hline FOUNDER & LLC "Consulting Publishing Company "Business Perspectives" \\
\hline
\end{tabular}

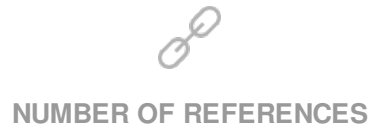

33
NUMBER OF FIGURES

2
NUMBER OF TABLES

4

(C) The author(s) 2023. This publication is an open access article. 


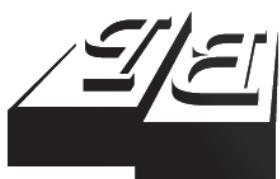

BUSINESS PERSPECTIVES

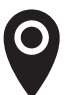

LLC "CPC "Business Perspectives" Hryhorii Skovoroda lane, 10, Sumy, 40022, Ukraine

www.businessperspectives.org Accepted on: $19^{\text {th }}$ of February, 2018

(c) Alaa M. Soliman, Adam Mukhtar, Moade F. Shubita, 2018

Alaa M. Soliman, Dr., Economics, Leeds Beckett University, UK.

Adam Mukhtar, Dr., Head Office, Zenith Bank, Victoria Island, Nigeria.

Moade F. Shubita, Dr., Accounting and Finance, Leeds Beckett University, UK.

\section{THE LONG-TERM RELATIONSHIP BETWEEN ENTERPRISE RISK MANAGEMENT AND BANK PERFORMANCE: THE MISSING LINK IN NIGERIA}

Received on: $4^{\text {th }}$ of November, 2017 Analytics and International Business,

\begin{abstract}
This study investigates the relationship between Enterprise Risk Management adoption and implementation, and the performance of banks using a sample of four out of the seven Strategically Important Banks (SIB) listed on the Nigerian Stock Exchange covering the period from 2005 q1 to 2015 q2. In this study, the authors determined a measure for Enterprise Risk Management (ERM) adoption or implementation (ERM index) using an integrated Enterprise Risk Management measurement model for the banking sector suggested by Soliman and Mukhtar (2017). A time series Johansen's cointegration test was used to obtain evidence of the long-term association between ERM and performance, while Vector Error Correction Model (VECM) analysis was performed to gather evidence of causality relationship between ERM and performance. Finally, Generalized Impulse Response Function was used to obtain evidence of how performance responds to the introduction of a shock on Enterprise Risk Management. This study makes significant contributions to the existing body of knowledge, as it yields the first Enterprise Risk Management-performance-based empirical results that indicate a long-term relationship, causation effects, in addition to responding to performance ERM.
\end{abstract}

\section{Keywords}

JEL Classification
ERM, Nigerian banking sector, firm performance, longterm relationship, causation, impulse response

\section{INTRODUCTION}

In recent years, Enterprise Risk Management (ERM) as a discipline has received unprecedented interest and international attention (Arena et al., 2010). This has resulted in many leading organizations adopting ERM as their risk management framework (Beasley et al., 2006). Empirical investigations into the global level of ERM adoption have indicated that an increasing number of firms are embracing ERM. For example, a survey conducted by Deloitte in 2008 on 151 firms in various regions: North America 56, South America 24, Europe 68 and others three firms, found a growing interest in ERM among firms with a majority of respondents; 64 percent in Europe and 62 percent in North America. Such results indicate that their interest in ERM was higher compared with the previous year to the current survey. The survey also found that 56 percent of the firms had implemented ERM programs for no more than two years before the year of the survey; thus signalling the growing trend in ERM adoption (Deloitte, 2008).

This is an Open Access article, distributed under the terms of the Creative Commons Attribution-NonCommercial 4.0 International license, which permits re-use, distribution, and reproduction, provided the materials aren't used for commercial purposes and the original work is properly cited.
An important feature of an ERM programmed embarked upon by any firm is that it is designed for a medium to long-term benefit rather than the short-term. In this regard, one would expect ERM-performance based studies to be focused on determining the medium to long-term 
effects of ERM adoption and implementation. This is, however, not the case, as all the ERM-performance related studies conducted before this study have used data analysis techniques that do not capture the medium to long-term effects. We note that the study undertaken by Pagach and Warr (2010) attempted to investigate the effects of adopting ERM on a firm's long-term performance, but failed to use time series data analysis techniques that could provide evidence of the durable relationship between ERM and performance. To fill this major research gap, we adopted time series data analysis techniques such as cointegration, causality and impulse response tests to establish the presence or otherwise of any long-term, causal and impulse response relationships between ERM and performance. Our main objective of performing time series data analysis is to explain some important relationships among our variables, such as: the long-term relationship, causal relationship and impulse response effects. Such analysis is vital to our study because implementation of ERM by firms is a long process. Hence, the benefit of implementing ERM is expected to manifest in the medium and long term rather than in the short term (Pagach et al., 2010; Eckles et al., 2011). We note that, despite the vital medium to long-term features of ERM benefits, there is no study on ERM-performance relationship that is based on time series analysis aimed at establishing long-term, causal and impulse response relationships. The research question that remains unanswered in the ERM literature is whether there is a long-term relationship between ERM and performance. Therefore, our time series analysis is novel in this research area. The main contribution of this study is that, for the first time, it provides financial sector regulators and operators with an empirical evidence of the medium to long-term effects of ERM. The remainder of this paper is structured as follows. First, we present the conceptual framework followed by a summary of relevant and related literature on the empirical evidence of the relationship between ERM and performance. We then present the methodology, followed by an analysis of the empirical results. Finally, we conclude by summarizing our findings and provide a conclusion.

\section{LITERATURE REVIEW}

ERM is generally considered as a paradigm shift from 'silo-based' approach of managing risk to a holistic approach to managing risk. There is a theoretical expectation that, when firms adopt and/or implement an ERM program, they derive several benefits. These include keeping all their risks within a defined risk tolerance limits, and improvement in performance and market values, among other benefits (Pagach \& Warr, 2010, 2011; Arena et al., 2010). Prior to this study, other empirical studies have attempted to determine whether the theoretical anticipated benefits of ERM are achieved. Indeed, some studies (see for example, Gates et al., 2012; Obalola et al., 2014; Baxter et al., 2013; Ping et al., 2015) provide empirical evidence that firms reap the expected benefits of ERM in practice, which include enhanced performance. Conversely, other empirical studies by Pagach and Warr (2007, 2010, and 2011), Beasley et al. (2008), Quon et al. (2012) and Ramlee et al. (2015) could not find such evidence of firms benefiting from ERM adoption by way of improvement in performance. There is another body of literature (see for example, Bunea, 2014; Song \& Zeng, 2014) focused on capital regulation in general and bank-risk taking and found that regulation of financial institutions brings stability by improving performance.

The ERM-performance related studies cited above have used data analysis techniques that are not capable of determining the medium to long-term effects of ERM on the performance of firms, however, the study by Pagach and Warr (2010) attempted to investigate the effects of adopting ERM on firm's long-term performance. Because ERM programs are designed and implemented over a long period, the results of an ERM implementation are expected to manifest over a longterm horizon fully (Pagach et al., 2010; Eckles et al., 2011). Nonetheless, the literature on ERM has not paid the required attention to the long-term relationship between ERM implementation and performance.

According to The Casualty Actuarial Society (2003), ERM enables firms to monitor risks from all sources, thereby resulting in increasing the firms' short- and long-term value to stakeholders. Additionally, Pagach et al. (2010) and Eckles et al. (2011) have argued that a firm's investment in an 
ERM program takes a long time for the expected benefits to be realized. This implies a theoretical expectation of long-term relationship of ERM and performance. An empirical study conducted by Obalola et al. (2014), which investigated the effects of ERM adoption by Nigerian insurance firms, using data collected over a 10 -year period, found evidence of continuous improvement in the performance of insurance firms that adopted ERM. Although the focus of that study was not to determine any long-term relationship between ERM and performance, the fact that 10 -year data was used indicates that the results of the study cover a long-term horizon. In another empirical study by Pagach and Warr (2010), the effects of ERM adoption on long-term performance of firms were investigated but little impact of ERM adoption on the performance of firms was revealed.

One major theoretical expectation of ERM is that its adoption causes or results in better performance of the adopting firm. This is indicated in several definitions of ERM such as: Arena et al. (2010) and Hoyt et al. (2010). This is an implicit indication that ERM adoption is expected in theory to have a causality effect on firms' performance. Although to the best of our knowledge no empirical study has conducted a direct investigation into the causality relationship between ERM and performance, we note that certain empirical studies have adopted methodologies from which we can infer the examination of causality relationship. For example, the study by Hoyt et al. (2010), which used the announcement of Chief Risk Officer (CRO) appointment or presence of similar position in a firm to signal ERM adoption, found a positive and significant relationship between announcement of CRO appointment (a proxy for ERM) and performance. Conversely, Pagach and Warr (2010) used the announcement of CRO appointment as a signal to ERM adoption, but failed to find significant evidence that announcement of CRO appointment (a proxy for ERM) caused changes in performance measures. We argue here that, the fact that the reactions of performance measures were tested against one-off event (announcement of CRO appointment) implies an expectation that the one-off event could cause an effect on the selected performance measures. In other words, if a selected performance measure of a firm, such as share price, is expected to react simply because the firm has announced the appointment of CRO, then the reaction of the share price, in this case, can be said to have been caused by the announcement of CRO appointment (proxy for ERM).

Previous research studies were mainly focused on the short-term effects of ERM with little or no evidence given on the long-term relationship between ERM and bank performance. The main contribution of this study is that, for the first time, it provides empirical evidence of the medium to long-term effects of ERM on bank performance using various statistical techniques.

\section{CONCEPTUAL FRAMEWORK AND RESEARCH HYPOTHESES}

A critical foundation upon which this study rests is the fact that, theoretically, ERM adoption or implementation by firms is expected to translate into improved performance and value of firms. This is achieved by decreasing earnings and stock-price volatility, reducing external capital and increasing capital efficiency (Arena et al., 2010; Pagach \& Warr, 2010, 2011; Beasley et al., 2008). Several empirical studies have supported this theoretical expectation of the benefits of ERM adoption by firms. These include, Soliman and Mukhtar (2017), Obalola et al. (2014), Ping et al. (2015), Andersen (2008), McShane et al. (2011) and Baxter et al. (2013). Building on these studies that provide empirical evidence that ERM adoption does result in performance improvement of firms, and with similar theoretical expectation at the background, we develop a theoretical framework with two hypotheses. Firstly, ERM adoption and implementation are positively related to the long-term performance of Nigerian banks. Secondly, the performance of Nigerian banks responds positively to a positive shock on ERM. The conceptual framework for the model is presented in Figure 1.

The conceptual framework presented in Figure 1 indicates that ERM has short and long-term association with, and causation effects on, firm value. Moreover, firm value responds to shock on ERM. 


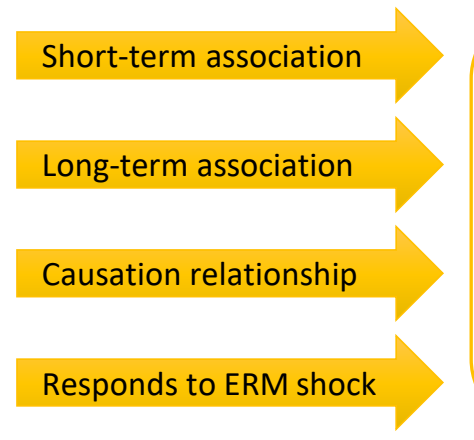

\section{Performance measures}

- Firm value - FV

- Return on average equity - ROAE

Figure 1. The conceptual framework for the study

\section{METHODOLOGY}

To facilitate our time series analysis, we selected an important category of banks in the Nigerian banking sector, which is the group of banks designated by the CBN as SIBs. Out of the total of eight banks that make up this list of SIBs in Nigeria, we eliminated one bank that is neither listed on the Nigerian Stock Exchange nor has an international authorization. The remaining seven SIBs were grouped by total assets as of December 31, 2014, and selected the top four banks regarding total assets. We argue that using a much smaller sample for our time series analysis will facilitate more indepth analysis that can be reasonably generalized to the entire population of similar banks.

The main independent variable in this study is ERM index while two dependent variables (i.e. return on average equity - ROAE and firm value - FV) were used. For the ERM index, we used an integrated model for measuring ERM implementation for the banking sector that was first suggested by Soliman and Mukhtar (2017) as a way of addressing the serious limitations associated with ERM measurements. We obtained the relevant quantitative and qualitative information as required by the integrated ERM models from the published quarterly and annual reports of the selected banks, which we applied to the relevant model to obtain the ERM index for the relevant periods for each bank.

For return on average equity, profit after tax divided by average equity was obtained for all the sampled banks over the period under study. With regard to the firm value, we used the Tobin's $Q$, which is considered the most commonly used measure of firm value in empirical risk management studies (Hoyt et al., 2010; McShane et al., 2011). We adopted the definition of Tobin's $Q$ as used by Cummins et al. (2006) and Hoyt et al. (2010) as the market value of equity plus the book value of liabilities divided by the book value of assets. We obtained the total market capitalization of our sampled banks from the Nigerian Stock Exchange, and this represents the market value of equity. The book values of assets and liabilities were obtained from published financial reports of the sampled banks.

For our time series analysis, we obtained the quarterly ERM index, ROAE and FV from the first quarter of 2005 to the second quarter of 2015; thus making a total of 42 quarters. We restricted our historical data to 2005 because the sector experienced significant reform through consolidation, which reduced the number of commercial banks in Nigeria from 89 to 25 (Agusto \& Co., 2010). To ensure consistency of data and maintain the identities of our sample banks over the time frame, we selected the post-consolidation period (i.e. 2005) as the start date for our time series data analyses.

\subsection{Empirical results and discussion}

First, we performed ADF unit root tests to determine the suitability of our variables of interest (i.e. ERMI, ROAE and FV) for co-integration analysis. To conclude that a variable is suitable for co-integration test, such variable must be non-stationary (i.e. has a unit root) at level and stationary (i.e. no unit root) at first difference. To achieve such an 
Table 1. ADF tests for ERM, ROAE, and FV

\begin{tabular}{|c|c|c|c|c|c|c|}
\hline \multirow[b]{2}{*}{ Variables } & \multicolumn{3}{|c|}{ At level* } & \multicolumn{3}{|c|}{ At first difference* } \\
\hline & With intercept & $\begin{array}{l}\text { Trend and } \\
\text { intercept }\end{array}$ & $\begin{array}{l}\text { No trend, no } \\
\text { intercept }\end{array}$ & $\begin{array}{l}\text { With } \\
\text { intercept }\end{array}$ & $\begin{array}{l}\text { Trend and } \\
\text { intercept }\end{array}$ & $\begin{array}{l}\text { No trend, } \\
\text { no intercept }\end{array}$ \\
\hline ERM & $-2.3335^{*}$ & $-3.0327^{*}$ & $0.4733^{*}$ & -7.9610 & -7.8910 & -7.9196 \\
\hline ROAE & $-2.8186^{*}$ & $-2.7811^{*}$ & $-0.7391 *$ & -10.551 & -10.472 & -10.690 \\
\hline $\mathrm{FV}$ & $-1.5299^{*}$ & $-2.5926^{*}$ & $-0.1882^{*}$ & -6.2037 & -6.1017 & -6.2679 \\
\hline
\end{tabular}

Note: Lag Length: 0 (Automatic - based on SIC, max lag =9). An asterisk indicates significant at 5\% significance level.

outcome, we must accept the null hypothesis at the level and reject it at first difference.

The results of ADF unit root test, in Table 1, for ERMI, ROAE and FV at level show that non-stationarity cannot be rejected at five percent significance level. Moreover, the ADF at first difference of ERM, ROAE and FV indicates that the null hypothesis of non-stationarity is rejected in all three cases at 5 percent significance level.

The next step is to carry out Johansen's co-integration test using the optimal lag value of seven based on Akaike's Information Criterion. The test was run under the null hypothesis that 'there is no co-integration' and the alternative hypothesis whereby 'there is co-integration'. Both null and alternative hypotheses were related to levels of cointegration being test.

The results presented in Table 2 of Johansen's cointegration test indicate that both 'Trace statistic' and 'Max-Eigen statistic' provided consistent and corroborative evidence of the existence of co-integration among our variables. With such evidence, we can conclude that, ERMI, ROAE and FV are co-integrated, that is, they have a long-term association. This conclusion is very critical to this study as it provides empirical evidence that ERM

Table 2. Johansen co-integration test adoption (ERMI) has long-term relationship with performance (ROAE and FV).

The evidence of co-integration obtained implied that ERM implementation by banks has long-term association with their performance. The evidence of long-term association between ERM and firm performance is consistent with the theoretical benefit expected from an ERM program as expressed by The Casualty Actuarial Society (2003). This posited that ERM enables firms to monitor risks from all sources which results in increasing the firm's short and long-term value to stakeholders. Additionally, Pagach et al. (2010) and Eckles et al. (2011) have argued that a firm's investment in an ERM program takes a long time to realize the expected benefits, which also implies a theoretical expectation of long-term relationship of ERM and performance. Empirically, our finding is somewhat consistent with that of Obalola et al. (2014). They investigated the effects of ERM adoption by Nigerian insurance firms, using data collected over a 10-year period, and found evidence of continuous improvement in the performance of insurance firms that adopted ERM. However, that study did not strive to determine the longterm relationship between ERM and performance. Nevertheless, our finding contradicts that of Pagach and Warr (2010), who investigated the ef-

\begin{tabular}{|c|c|c|c|c|}
\hline \multicolumn{5}{|c|}{ Unrestricted co-integration rank test (maximum eigenvalue) } \\
\hline $\begin{array}{l}\text { Hypothesized } \\
\text { No. of } C E(s)\end{array}$ & Eigenvalue & Trace statistic & Critical value & P-value \\
\hline None* & 0.692093 & 40.05060 & 21.13162 & 0.0000 \\
\hline At most $1^{*}$ & 0.537498 & 26.21751 & 14.26460 & 0.0004 \\
\hline At most $2^{*}$ & 0.132947 & 4.850259 & 3.841466 & 0.0276 \\
\hline
\end{tabular}

Note: An asterisk denotes rejection of the hypothesis at the $5 \%$ significance level; Trace test indicates 3 co-integrating equation(s) at the 5\% significance level; Max-eigenvalue test indicates 3 co-integrating equation(s) at the $5 \%$ significance level. 
fects of ERM adoption on the long-term performance of firms but found little impact of ERM adoption on performance.

We then conducted the VEC Granger causality test using $\mathrm{FV}$ as the dependent variable with ERMI and ROAE as the independent variables.

From Table 3, the corresponding p-values of the Chi-square statistic under the two pair of the hypotheses (ERMI does not Granger cause FV and ROAE does not Granger cause FV) are less than 5 percent. In other words, we cannot accept both null hypotheses. Hence, we reject them and conclude that both ERMI and ROAE Granger cause FV. Because ERMI is the main independent variable in this study, we conclude that the dataset used in this study provided significant evidence that ERMI causes FV; thereby establishing a causality relationship between ERM and performance of Nigerian banks.

The evidence of causality relationship between ERM adoption/implementation and performance of banks obtained is consistent with the theoretical expectation that adopting an ERM program causes or results in improved performance. The theoretical expectation that ERM adoption causes or results in better performance is pervasive in several definitions offered on ERM; for example, COSO (2004), Beasley et al. (2008), Gordon et al. (2009), Hoyt et al. (2010), Arena et al. (2010), and Pagach and Warr $(2010,2011)$.

Table 3. Granger causality test under VEC environment

\begin{tabular}{l|c:c}
\hline \multicolumn{3}{c}{ Dependent variable: $\mathbf{D}(\mathbf{F V})$} \\
\hline $\mathrm{D}(\mathrm{ERMI})$ & 27.78603 & 0.0002 \\
\hline $\mathrm{D}(\mathrm{ROAE})$ & 19.86085 & 0.0059 \\
\hline
\end{tabular}

In undertaking the VECM tests, we developed VECM that has FV as the dependent variable with ERMI and ROAE as the independent variables. General model analysis, as presented in Table 4, reveals an R-squared value of 86.99 percent; thereby implying that more than $85 \%$ of the variation in the dependent variable (FV) is explained by the independent variables (ERMI and ROAE). Furthermore, the model has an F-statistic value of 3.3418 with a corresponding p-value of 2.12 percent, which is less than
5\%. This indicates that ERMI and ROAE have joint statistical significance to FV. From the residual diagnostic analysis, the results indicate some strength in the model, which passed two of the three residual diagnostic tests performed. Firstly, the serial correlation test result outlined in Table 4 demonstrates that the BreuschGodfrey Serial Correlation LM Test produced an observed R-squared value of 26.4367 with a corresponding p-value of 0.04 percent. Since the $\mathrm{p}$-value is less than 5 percent, we cannot accept the null hypothesis (there is no serial correlation in the regression residuals) instead, we reject it and conclude that there is a serial correlation in the residuals. This conclusion indicates a weakness in the model. In the second residual diagnostic test, we checked for heteroscedasticity in the residuals using the Breusch-PaganGodfrey method, which produced an observed R-squared value of 17.5029 with a corresponding $\mathrm{p}$-value of 82.64 percent. Since the $\mathrm{p}$-value is more than 5 percent, we cannot reject the null hypothesis ('there is no heteroscedasticity in the regression residuals'). Thus we accept it and conclude that there is no heteroscedasticity in the residual. The third residual diagnostic test relates to testing if the residuals follow a normal distribution, which is a key feature of a good model. The result of our Histogram Normality Test reveals a Jarque-Bera statistic value of 2.2544 with a corresponding $p$-value of 32.39 percent. Since the corresponding $p$-value is less than 5 percent, we cannot reject the null hypothesis (the regression residuals are normally distributed), rather we accept it and conclude that the residuals in our model are normally distributed. Our residual diagnostic test summarizes that we have established that, the residuals do not have heteroscedasticity and are normally distributed, which are positive signs for a good model. However, the serial correlation in the residuals reduces the 'goodness of fit' of the model.

The second aspect of our VECM review is to check for causality relationships among the variables. In the first place, we note from Table 4 , the negative sign of $\mathrm{D}(\mathrm{FV}) \mathrm{C}(1)$ Coefficient, which gives an initial indication of the possibility of long-run causality from ERMI and ROAE to FV. This is further corroborated by the $\mathrm{D}$ (ERMI) 
Table 4. VECM with Firm Value (FV) as the dependent variable

\begin{tabular}{|c|c|c|c|}
\hline $\begin{array}{l}\text { Dependent: FV } \\
\text { Independent: ERMI and ROAE }\end{array}$ & $\begin{array}{l}\text { VEC estimate } \\
\text { D(FV) }\end{array}$ & Wald test ERMI & $\begin{array}{l}\text { Wald test } \\
\text { ROAE }\end{array}$ \\
\hline $\mathrm{D}(\mathrm{FV}(-1))$ Coefficient & -0.5302 & & \\
\hline $\mathrm{D}(\mathrm{FV}(-1))$ Standard error & 0.2597 & & \\
\hline $\mathrm{D}(\mathrm{FV}(-1)) \mathrm{t}$-value & -2.0417 & & \\
\hline $\mathrm{D}(\mathrm{FV})$ R-squared & 0.8699 & & \\
\hline $\mathrm{D}(\mathrm{FV})$ F-statistic & 3.3418 & & \\
\hline $\mathrm{D}(\mathrm{FV})$ F-statistic $p$-value & 0.0212 & & \\
\hline$D(F V) C(1)$ Coefficient & -0.2381 & & \\
\hline$D(F V) C(1) p$-value & 0.0021 & & \\
\hline Chi-square statistic & & 27.7860 & 19.8608 \\
\hline Chi-square $p$-value & & 0.0002 & 0.0059 \\
\hline \multicolumn{4}{|l|}{ Serial correlation test } \\
\hline Observed R-squared value & 26.4367 & & \\
\hline Chi-square $p$-value & 0.0004 & & \\
\hline \multicolumn{4}{|l|}{ Heteroscedasticity test } \\
\hline Observed R-squared value & 17.5029 & & \\
\hline Chi-square $p$-value & 0.8264 & & \\
\hline \multicolumn{4}{|l|}{ Normality test } \\
\hline Jarque-Bera & 2.2544 & & \\
\hline P-value & 0.3239 & & \\
\hline
\end{tabular}

Note: Serial correlation test method is Breusch-Godfrey Serial Correlation LM Test; Null hypothesis: 'there is no serial correlation in the regression residuals'. Heteroscedasticity method is Breusch-Pagan-Godfrey; Null hypothesis: 'there is no heteroscedasticity in the regression residuals'. Normality test method is Histogram Normality Test; Null hypothesis for normality test: 'the regression residuals are normally distributed'.

C(1) p-value of 0.21 percent, which is less than 5 percent (see Table 4). The combined effects of the negative sign of $\mathrm{D}(\mathrm{FV}) \mathrm{C}(1)$ Coefficient and the $\mathrm{D}$ (ERMI) $\mathrm{C}(1) \mathrm{p}$-value, which is less than 5 percent, imply that there is a long-term causality relationship from ERMI and ROAE to FV. We can, therefore, conclude that, in the long run, our independent variables (ERMI and ROAE) cause our dependent variable FV.

With regard to establishing the possibility of a short-run relationship between our variables, the Wald test result of the ERMI coefficient indicates a Chi-square statistic of 27.7860 and a corresponding $\mathrm{p}$-value of 0.02 percent (see Table 4). Since the corresponding p-value is less than 5 percent, we reject the null hypothesis (there is no short-run causality from the independent to the dependent variables) and accept the alternative hypothesis. Hence, we conclude that the coefficients of the independent variable are zero, meaning that there is short-run causality from the ERMI to FV.

For the second Wald test of this model (ROAE), the results indicate a Chi-square statistic of 19.8608 and a corresponding p-value of 0.59 percent, as presented in Table 4. Again, since the corresponding $\mathrm{p}$-value is less than 5 percent, we reject the null hypothesis and accept the alternative hypothesis, thus concluding that there is short-run causality from ROAE to FV.

The overall result of our VECM is that it provides strong evidence of causality relationship from ERMI and ROAE to FV in the long term, alongside short-run individual causality relationship from ERMI to FV. Based on this evidence, we can, therefore, conclude that ERM has both long- and short-term causality rela- 
tionships with the performance of Nigerian banks as measured by FV.

Another important test performed as part of data analysis is the impulse response analysis (IRA) in which we examined the speed with which a 1 percent standard deviation shock in one variable affects the current, as well as future values of other variables over a specified period. In running our IRA, we introduced positive shock of one standard deviation of the variables in the model to see the reactions of the variables. Because our data is gathered on a quarterly basis, we selected 42 periods, which is equivalent to the length of our time series data. Moreover, this length of time horizon provides us with a long-term view of the response of performance measures to an impulse on ERM.

The results of impulse response analyses as presented in Figure 2 yield interesting reactions of different variables to an introduction of one standard deviation positive shock to other variables. Although we value the importance of the response of each of the variables to an introduction of a positive shock on all other variables, we consider the response of ROAE and FV to a positive shock on ERMI to be more relevant to our study. This is because the focus of our study is to determine the effects if any, of ERMI on performance (FV and ROAE). From the impulse response graph, FV and ROAE responded differently to a positive shock on ERMI both within the range of positive values without assuming negative values. The response of FV to a positive shock on ERMI was relatively neutral at the beginning but later fluctuated mildly within the first five quarters, followed by more volatile fluctuations up to the tenth quarter before returning to mild fluctuation and finally assuming equilibrium after quarter twenty. This implies that if the ERMI of a firm receives a positive shock, it takes about three quarters for it to impact positively the FV of the firm with the impact increasing along quarters and gradually returning to equilibrium. Conversely, a positive shock on ERM receives an almost immediate response from ROAE, which fluctuates sharply within the first 10 quarters, assuming mildness in the fluctuation after quarter 10 and, thereafter, settling at equilibrium after quarter 20 . This implies that, if the ERM of a firm receives a positive shock, ROAE responds immediately with the magnitude of response reducing over time until equilibrium is restored after year 20 .

It is noteworthy that the two variables in this study (ROAE and FV) exhibit some similarities regarding their response to an introduction of one standard deviation positive shock on the main variable (ERMI). In the first place, both ROAE and FV responded by series of fluctuations but did not assume zero values within the 42 quarter time horizon. This is consistent with our expectation that ROAE and FV are positively related to ERM. Hence, a positive effect on ERM should, all other things being equal, result in a positive response from ROAE and FV. Though some downward trends were observed, we note that such downward trends were not sufficiently significant to push ROAE and FV to assume zero values; hence, maintaining their positive relationships with ERMI. The second major similarities exhibited by the response of ROAE and FV to a positive shock on ERM is the fact that equilibrium levels were restored after quarter 20, which is five year horizon, thus reflecting the long-term association between ERMI and performance of firms.

Relating our observed trend of responds of performance measures to a shock in ERM, we argue that it corroborates the findings of the positive relationship between ERM and performance of banks (both long- and short-term) as well as the causality relationship established between ERM and performance of banks. We also note that, in responding to a positive shock to ERM, our performance measures did not assume negative values. This is consistent with the theoretical expectation that by implementing an ERM program, a firm's performance is expected to respond positively (COSO, 2004; Beasley et al., 2008; Gordon et al., 2009; Hoyt et al., 2010; Arena et al., 2010; Pagach et al., 2010, 2011; Paape et al., 2012). Although no empirical study has investigated specifically the impulse response relationship of ERM and performance, we hold that empirical evidence of performance reacting to one-off ERM event (announcement of CRO appointment) obtained by Hoyt et al. (2010) can be used to draw an inference of performance responding to the ERM event. 

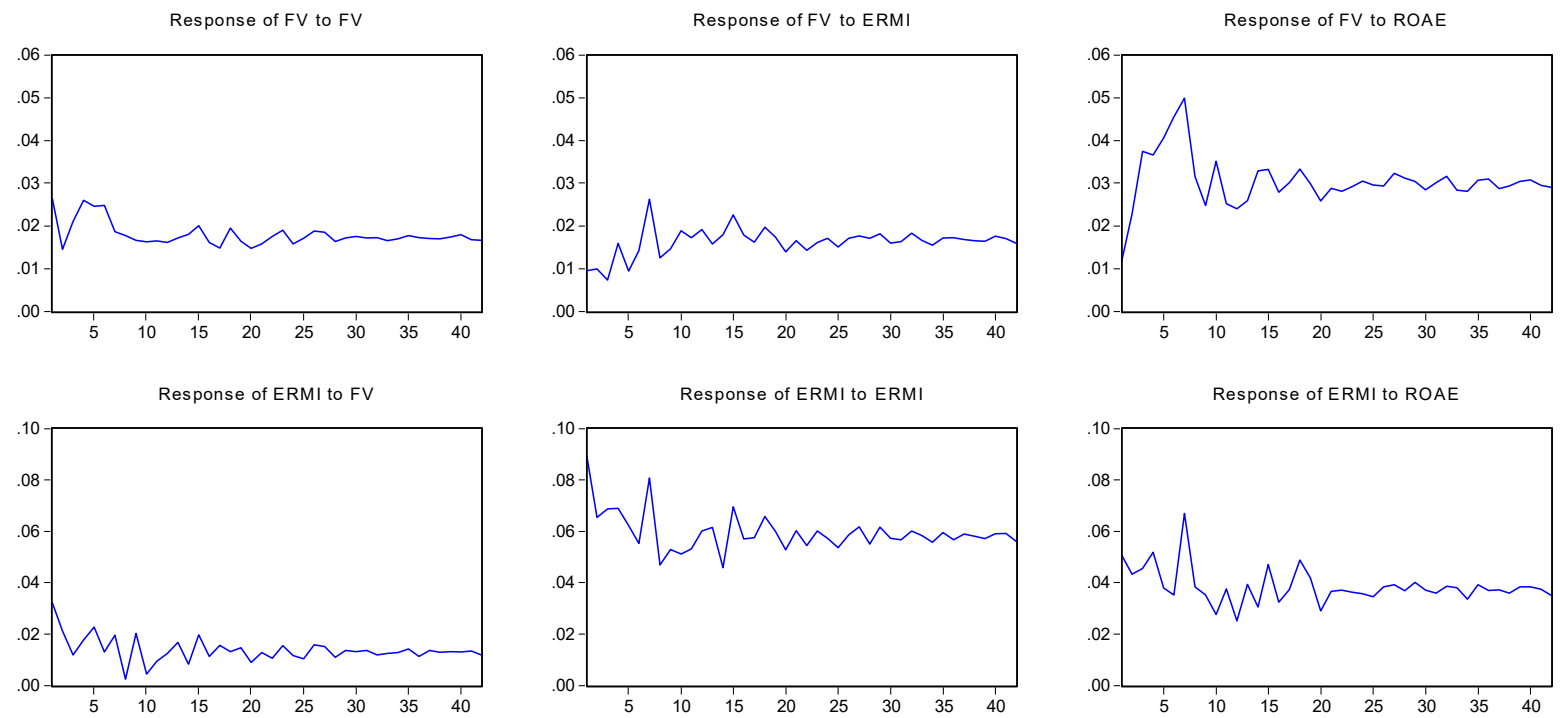

Response of ROAE to FV
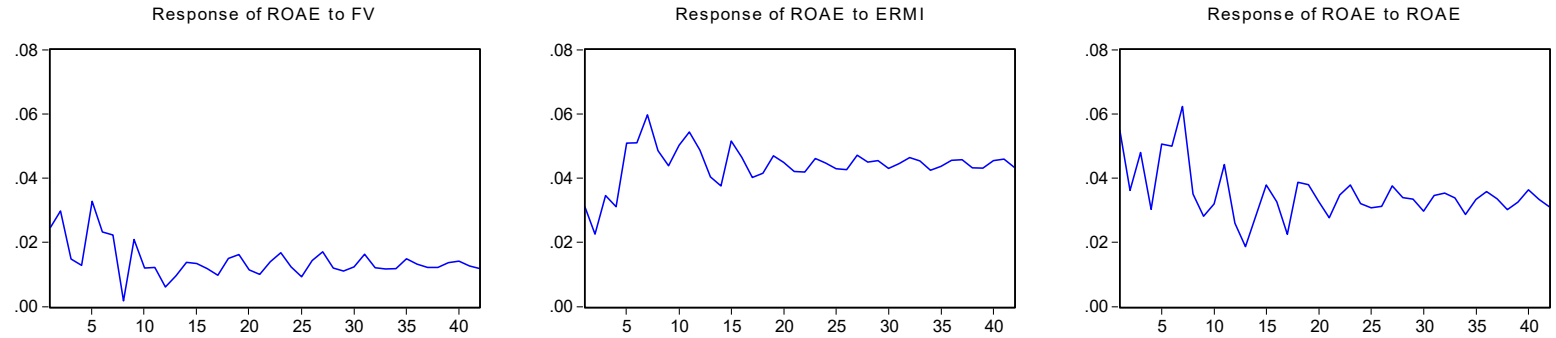

Figure 2. Graphical result of generalized impulse response analysis

\section{CONCLUSION}

In this study, we found significant empirical evidence that ERM does affect the performance of Nigerian banks in both the short and long terms. Moreover, the study has provided empirical evidence that ERM has a causation effect on the performance of Nigerian banks and evidence was obtained that the performance of Nigerians banks responds positively to a positive shock on ERM. The evidence of cointegration obtained implied that ERM implementation by banks has a long-term association with their performance. In other words, our cointegration results provided significant evidence of long-run association between ERM and performance of Nigerian banks. Furthermore, the study provided evidence of the causality relationship between ERM and performance measures; thereby implying that the adoption or implementation of an ERM program leads to improvement in the performance of Nigerian banks, both in the short and long terms. Furthermore, this study provides evidence of how the performance of Nigerian banks (represented by ROAE and FV) responds to the introduction of one standard deviation positive shock to ERM. The evidence obtained from our IRA indicates that the performance of Nigerian banks responds positively to the introduction of a positive shock on ERM with series of volatile upward and downward trends in the first five quarters, assuming more stable trends thereafter and finally returning to equilibrium in quarter 20.

Based on this study and considering the strength of the evidence obtained, we affirm the hypotheses for this study and conclude that the adoption and implementation of ERM by Nigerian banks are positively related to their performance in the long run. Moreover, the performance of Nigerian banks responds 
positively to a positive shock on ERM. The relationship between ERM and bank performance provides evidence to policy makers on the significant role that ERM can play in enhancing performance.

We argue that, by making such a significant contribution to the literature on ERM and bank performance, we have set the pace for future researchers to consider using more comprehensive performance indicator models in measuring ERM implementation and the impact on performance, which will go a long way to improve the quality of research in this overlooked research area.

\section{REFERENCES}

1. Agusto and Agusto, \& Co Research (2010). Banking Industry Report. Lagos: Agusto \& Co. Ltd.

2. Andersen, T. (2008). The Performance Relationship of Effective Risk Management: Exploring the Firm-Specific Investment Rationale. Long Range Planning, 41(2), 155-176.

3. Arena, M., Arnaboldi, M., \& Azzone, G. (2010). The organizational dynamics of enterprise risk management. Accounting, Organizations and Society, 35(7), 659-675.

4. Baxter, R., Bedard, J. C., Hoitash, R., \& Yezegel, A. (2013).

Enterprise risk management program quality: Determinants, value relevance, and the financial crisis. Contemporary Accounting Research, 30(4), 1264-1295.

5. Beag, F., \& Singla, N. (2014). Cointegration, Causality and Impulse Response Analysis in Major Apple Markets of India. Agricultural Economics Research Review, 27(2), 289-298. https://doi.org/10.5958/09740279.2014.00032.9

6. Beasley, M. S., Clune, R., \& Hermanson, D. R. (2006). The Impact of Enterprise Risk Management on the Internal Audit Function. North Carolina State University. Retrieved from: http:// erm.ncsu.edu/az/erm/i/chan/marticles/documents/ERMJFAPaper21306.pdf

7. Beasley, M., Pagach, D., \& Warr, R. (2008). Information conveyed in hiring announcements of senior executives overseeing enterprisewide risk management processes. Journal of Accounting, Auditing \& Finance, 23(3), 311-332.
8. Bunea, M. G. N. (2014). Basel III Impact on Romanian Banking System Performance. SEA Practical Application of Science, 3 , 397-403.

9. Committee of Sponsoring Organisations of the Treadway Commission (2004). Enterprise Risk Management - Integrated Framework. New York: COSO.

10. Deloitte (2008). Perspectives on ERM and the Risk Intelligent Enterprise. Enterprise Risk Management Benchmark Survey. Deloitte Development LLC. Retrieved from http://www. ipai.pt/fotos/gca/surveyerm pt_1_1233338524.pdf

11. Dong, J., Pan, H., Yao, Y., Luo, Y., \& Yang, X. (2012). Empirical Study on Dynamic Transmission of Volatility among Financial Markets. Journal of Convergence Information Technology, 7(21), 323-332.

12. Eckles, D., Hoyt, R., \& Miller, S. (2011). The Impact of Enterprise Risk Management on the Marginal Cost of Reducing Risk: Evidence from the Insurance Industry. Journal of Banking \& Finance, 43, 247-261.

13. Gates, S., Nicolas, J., \& Walker, P. (2012). Enterprise Risk Management: A Process for Enhanced Management and Improved Performance. Management Accounting Quarterly, 13(3), 28-38. Retrieved from: https://www.questia.com/library/ journal/1G1-298614230/enterprise-risk-management-a-processfor-enhanced

14. Gordon, L., Loeb, M., \& Tseng, C. (2009). Enterprise risk management and firm performance: A contingency perspective. Journal of Accounting and Public Policy, 28(4), 301-327. http://dx.doi.org/10.1016/j.jaccpubpol.2009.06.006

15. Granger, C. W. J. (1969). Investigating causal relations by econometric models and crossspectral methods. Econometrica, 37(3), 424-438.

16. Gujarati, D. N. (2010). Econometrics by Example. Macmillan Publishers, London.

17. Gujarati, D. N., \& Porter, D. C (2010). Essentials of Econometrics (4th ed.). New York: McGraw-Hill International Edition.

18. Hoyt, R., \& Liebenberg, A. (2011). The value of enterprise risk management. Journal of Risk and Insurance, 78(4), 795-822. https://doi.org/10.1111/j.15396975.2011.01413.x

19. Koop, G., Pesaran, H., \& Potter S. M. (1996). Impulse response analysis in non-linear multivariate models. Journal of Econometrics, $74,119-148$

20. Kumar, S. (2014). Financial Development as an Instrument of Economic Growth in India: Evidence from Cointegration and Causality Analysis. IUP Journal of Applied Economics, 13(4), 28-41. Retrieved from: https://www.questia.com/library/ journal/1P3-3515971161/financial-development-as-an-instrument-of-economic

21. McShane, M., Nair, A., \& Rustambekov, E. (2011). Does enterprise risk management increase firm value? Journal of Accounting, Auditing \& Finance, 26(4), 641-658 
22. Obalola, M. A., Akpan, T. I., \& Abass, O. A. (2014). The Relationship between Enterprise Risk Management (ERM) and Organizational Performance: Evidence from Nigerian Insurance Industry. Research Journal of Finance and Accounting, 5(14), 152-161. Retrieved from: http:// www.iiste.org/Journals/index.php/ RJFA/article/view/14629

23. Obi, P., Miranda, P., \& Sil, S. (2011). An Inquiry into the Time Series Dynamics of Short-Term Rates and Stock Returns. Journal of Business \& Economic Studies, 17(1), 16-28.

24. Pagach, D., \& Warr, R. (2007). An Empirical Investigation of the Characteristics of Firms Adopting Enterprise Risk Management. North Carolina State University. Retrieved from: https://mgt.ncsu. edu/documents/Risk_officer_hazard_JBF.pdf

25. Pagach, D., \& Warr, R. (2010). The Effects of Enterprise Risk Management on Firm
Performance. Social Sciences Research Network. http://dx.doi. org/10.2139/ssrn.1155218

26. Pagach, D., \& Warr, R. (2011). The characteristics of firms that hire chief risk officers. Journal of Risk and Insurance, 78(1), 185-211. http://dx.doi.org/10.1111/j.15396975.2010.01378.x

27. Pesaran, H. H., \& Shin, Y. (1998). Generalized impulse response analysis in linear multivariate models. Economics Letters, 58(1), 17-21.

28. Ping, T. A., \& Muthuveloo, R. (2015). The Impact of Enterprise Risk Management on Firm Performance: Evidence from Malaysia. Asian Social Science, 11(22), 149-159. http://dx.doi. org/10.5539/ass.v11n22p149

29. Quon, T., Zeghal, D., \& Maingot, M. (2012). Enterprise Risk Management and Firm Performance. Procedia - Social and Behavioural Sciences, 62(24), 263-267.
30. Ramlee, R., \& Ahmad, N. (2015). Panel Data Analysis on the Effect of Establishing the Enterprise Risk Management on Firms' Performances. 4th European Business Research Conference 9-10 April 2015, Imperial College, London, UK.

31. Soliman, A. M., \& Mukhtar, A. (2017). Enterprise Risk Management and Firm Performance: An Integrated Model for the Banking Sector. Banks and Bank Systems, 12(2), 116-123.

32. Song, Q., Zeng, W. (2014). Basel III, risk aversion and bank performance: evidence from Chinese commercial banks panel data. International Conference on Social Science (ICSS 2014).

33. Yunus, N., Hansz, J., Kennedy, P. (2012). Dynamic Interactions between Private and Public Real Estate Markets: Some International Evidence. Journal of Real Estate Finance \& Economics, 45(4), 1021-1040. 